\title{
Environmental Ethics in Governing Recycled Material Styrofoam for Building Human Habitat
}

\author{
${ }^{1}$ Kartini Aboo Talib Khalid, ${ }^{2}$ Ravichandran Moorthy and ${ }^{3}$ Suhana Saad \\ ${ }^{1}$ Institute of Ethnic Studies, \\ ${ }^{2}$ School of History, Politics and Strategic, \\ ${ }^{3}$ School of Social, Development and Environmental Studies, \\ Faculty of Social Sciences and Humanities, \\ Universiti Kebangsaan Malaysia, 43000 Bangi, Selangor, Malaysia
}

Received 2012-04-08, Revised 2012-12-24; Accepted 2012-12-26

\begin{abstract}
Styrofoam is extensively used in food packaging businesses throughout the world. Its light weight makes it a favorite food package for entrepreneurs in food businesses. However, unlike its content, the food, which decomposed easily after some time, Styrofoam remains un-decomposed due to its oil-based structure. This study discusses the prospects of re-utilization of Styrofoam as environmentally friendly recycled material. This study uses the data from an exploratory survey on the usage of Styrofoam for food packagingconducted in the district of Bangi, Malaysia-to highlight the magnitude of Styrofoam-waste generated in these activities. The study shows that Styrofoam can be used in combination of cement and concrete to produce a light weight, energy efficient and strong building can be built. Since there are a lot of supplies of waste Styrofoam, this material can be re-used in as part of construction material. In addition the use of Styrofoam in construction could be an innovative way for constructing termite's free buildings. This study shows that recycling Styrofoam can assist in building environmentally friendly and cost efficient human habitat. Styrofoam can be channeled for a good cause and ways of governing the recycled materials. As such, the industrial waste generated by Styrofoam can be turned into other uses, thus reducing its environmental problems.
\end{abstract}

Keywords: Polystyrene, Styrofoam, Human Habitat, Governance, Bioethics, Environment Ethics, Recycle, Packaging Businesses, Environmentally Friendly, Waste Styrofoam

\section{INTRODUCTION}

The primary aim of this study is to discuss the prospects of re-utilizing waste polystyrene (or commercially known as Styrofoam) as environmentally friendly recycled material. This study is written based on an exploratory research approach. Schutt (2008) explains that exploratory research seeks not to test preformulated hypotheses but begins to discover what people think and how they act towards issues in some social setting. The study serves to outline ideas and discussions on Styrofoam that focuses on the possibility to recycle these waste materials into building environmental friendly human habitat. In many modern societies throughout the world, Styrofoam has found to be a use material in a variety of applications. However, its uses, especially in the food packaging businesses generates large amount of waste. The amount of waste Styrofoam is substantial when the context is expansive including states, countries and world. Therefore, turning a hard decompose waste materials into a variety of multiple usage particularly for building human habitat may seem practical to maximize the extensive amount of waste available.

\footnotetext{
Corresponding Author: Ravichandran Moorthy, School of History, Politics and Strategy, Faculty of Social Sciences and Humanities, Universiti Kebangsaan Malaysia, 43000 Bangi, Selangor, Malaysia Tel: +603-89215825 Fax: $+603-89213290$
} 
Styrofoam is an oil-based product, also known as extruded polystyrene. Styrofoam is utilized as disposable food service-ware such as containers, bowls, plates, trays, cartons and cups. These products are designed for onetime use for prepared foods for take outs and leftovers. Most restaurants, food retailers and food packagers who serve, provide, or pack prepared-food are likely to use Styrofoam as disposable food service-ware. The lightweight and colorless materials make it preferable for prepared food service-ware. Being light weight provides easy-to-carry containers that are strained free and the latter gives the meaning of sterile and hygiene that is effortless to differ from dirty containers.

However, Styrofoam contains health hazard risks to human when stored or heated because it may leach human carcinogen styrene into foods. Styrene is a chemical substance suspected of disrupting hormones that may harm the human body. The health hazard criterion in Styrofoam seems to be accepted in most prepared food businesses and consumers because the risk can be minimized by one-time utilization and by avoiding heat and long hour storage. Furthermore the availability, inexpensive nature and being easy to get at any grocery stores are added into the extensive use of Styrofoam.

Besides food-ware businesses, Styrofoam is used for packaging industries. Foam bubbles absorb shock and waterproof to keep fragile items safe. Being light weight also reduces shipping costs. Foam packaging is also flexible, strong and non-abrasive. The multiple use of foam makes it hard for businesses to find a substitution to it. Human and science have to be creative to manipulate foam in a way that will benefit human as well as the environment. However, Styrofoam is hard to decompose and it will occupy the landfill, thus it accumulates hazard to the environment and human. Plastics and Styrofoam have made waste management difficult. Moreover, it is extremely bulky and lightweight material makes it costly to recycle in small quantities. Many polymeric and polystyrene are labeled with symbols as an aid to recycling programs. These enhance major industrial users of polymeric and polystyrene to become creative in finding further uses of these materials. Recycle materials are a good business because prices for recycled materials are close to virgin materials, therefore profits can now be a motive. Polymeric and polystyrene manufacturers have become involved in recycling efforts to reproduce waste materials for various applications.

Evidently, a recycling program conducted by International Foam Solutions Inc (IFS) has introduced a Styro Solve System which reduces 90 percent of polystyrene foam and converts it into polygel, an environmentally friendly recyclable gel. The new form of polygel solves the issue of decomposition. A variety use of polystyrene may increase its value to industries whether modified or unmodified. Thus, another use of Styrofoam for building human habitat is no longer a fantasy. Styrofoam could contribute to efficiency in energy cost with some modification that is practical for building houses that could preserve heat and humidity. It could change the use of woods that may lead to reduce massive cut of priceless trees. Styrofoam may transform the way people build houses and it could be a practical way to a clean environment, especially when recycle materials are recycled for good causes. Thus, the human-environment interaction can be evaluated through human's creativity to protect their silent partner.

\section{MATERIALS AND METHODS}

This study uses the data from an exploratory survey on the usage of Styrofoam for food packaging-conducted in the district of Bangi, Malaysia-to highlight the magnitude of Styrofoam-waste generated in these activities. The findings of this survey are tabulated in Table 1 and discussed in the subsequent sub-sections. The study was conducted in the township of Bangi-a modern township in the suburb of Kuala Lumpur, Malaysiapredominantly residential and industrial area, with an estimated populace of about 150,000 inhabitants. The district also hosts a number of industrial and management training schools, colleges and a public university. A random observation suggests that the inhabitants are from the lower middle to upper middle income group. There are also numerous restaurants that cater for the food needs of the inhabitants. It is observed that the breakfast and lunch crowd is more significant in number compared to the dinner crowd. A plausible reason for is-the many factories and training and educational institutions draw people from outside the Bangi area for work and study purposes. These people would usually return to their homes outside Bangi after working hours. Random observations on numbers of stalls and restaurants in Bangi showed all of these food businesses used Styrofoam as their food-ware and prepared food-packages.

\section{RESULTS}

It is interesting to note that (as indicated from Table 1) Styrofoam is used widely as food packages in the eateries in the Bangi area. All eateries (both restaurants and hawker stalls) use Styrofoam food packages in their business. 
Table 1. Usage of Styrofoam food containers in Bangi area

\begin{tabular}{llll}
\hline Number of eateries in Bangi & $\begin{array}{l}\text { Daily usage of Styrofoam } \\
\text { food containers at all outlets }\end{array}$ & $\begin{array}{l}\text { Monthly usage of Styrofoam } \\
\text { food containers at all outlets }\end{array}$ & $\begin{array}{l}\text { Yearly usage of Styrofoam } \\
\text { food containers }\end{array}$ \\
\hline $\begin{array}{l}\text { Restaurants (in permanent building) } \\
-75 \text { outlets }\end{array}$ & 2,400 & 72,0000 & 864,00000 \\
$\begin{array}{l}\text { Hawkers (including night markets) } \\
-217 \text { outlets }\end{array}$ & 6,075 & 182,2500 & $2,187,0000$ \\
Total usage & 8,475 & 254,250 & $3,051,000$ \\
\hline
\end{tabular}

It is estimated that some 3,051,000 Styrofoam food packages are used annually-which means each Bangi resident uses an average of 20.34 Styrofoam food packages a year. If this figure is extrapolated to reflect the total usage of Styrofoam food packages by 28 million population of Malaysia, the figure will be quite staggering. These packages will then make their way to the rubbish bin and eventually end up in some waste landfillremaining there for generations.

This scenario is widespread through the country-it will not be an exaggeration to say that almost all (except for established chain of fast food eateries like McDonald and Kentucky Fried Chicken) eateries in the country use Styrofoam food packages in their business. As such, the waste generate from the use of this material is quite substantial and the effect to the environment is also quite adverse.

\section{DISCUSSION}

Until quite recently, the awareness among the public regarding the ill-effects of this waste material to the environmental has been rather minimal. While there have been some reports of the adversity of the Styrofoam usage, especially by the consumer organizations, the dissemination of such information among the public has been negligible. For the food business owners, the wide use of this material is attributed to its low costs, light weight, non-leaking features and its box like shapes with latches for easy packaging. The feedback received from the businesses also suggest that they a relative unaware of the ill-effects of this material to the environment-since nobody (including the authorities) have advised them on such a matter.

On a question whether they will avoid or reduce the use of Styrofoam (since they have now been made aware), most respondents say that they will continue using this material as other alternatives such as paper containers are more expensive and less hardy. Most of them also say that they will only change if there is a cheaper alternative or a ruling banning its use. They also say that they may consider a slight increase in food prices as their cost would have now increased. From the users, (public) perspective, the feedback also shows the lack of awareness on the environmental impacts of the use of this material. The random short interviews conducted shows that they prefer Styrofoam to paper containers due to its rigid structure-that can better support food such as soup and thick gravy perhaps not suitable for paper containers. Most of them say that they will support the use of other alternative packages but unwilling to pay the extra cost that comes with the use of such materials.

In the Malaysian scenario, there has not been a concerted effort to discourage the use of Styrofoam in food packaging. The government, in particulars the ministry of environment, ministry of health and the local municipalities, which have more control over the food businesses, should engage in efforts to educate the public on the negative effects of the use of Styrofoam and perhaps institute certain regulations and laws pertaining to deter the use of such material. Unfortunately, such initiatives from the authorities are clearly absent- many have attributed the-lag in policing'as the main reason for this problem. Although, the government, through various policies promoted the concepts of sustainability development and living as the part of their multipronged approach to mitigate climate change, there has not been any specific attention to the issue of Styrofoam. There is realization among the scholars that, in the Malaysian context, the change in the use of Styrofoam in food packaging business can only come through regulatory measures. The lack of awareness among the policy makers, especially those involved in the environment policies is definitely alarming.

\subsection{Environmental Ethics and New Ecology in Recycling}

Environmental ethics provides the necessary moral foundation regarding recycling initiatives (Moorthy et al., 2011). Habitat is a term used to describe non-human geographical areas occupied by species. Darwin referred to human as homo-sapiens, so habitat could be an acceptable term used to replace house or residence that are relatively familiar to the environment. Readings on 
habitat, human and environment are profound in the ecology terrain. Early research on ecology revolves around the relationship between organism and environment. The term new ecology has been used in the field of biological ecology (Colwell, 1984; 1992) and similar expressions such as dynamic ecology, discordant nature and ineluctably contingent nature can be found in this discourse (Worster, 1990; May and Seger, 1986). Even though these terms characterize many environmental systems that challenge system ecology, the process of agility and adaptation is evidence that nature tends to incline toward equilibrium (Odum, 1983; Margalef, 1968).

The new ecology perspective offers an approach to rethink the realm of human-environment relations (Zimmerer, 1994; Denevan, 1983; Smith, 1984). It suggests that nature lean toward stability and equilibrium. Thus, environmental management strategies that accommodate to change, risk and complexities are the new ecology agenda. The new ecology perspective within the sociology approach may have little interest in non-human organism, but the principle of stability and equilibrium prevails as a major concern. The idea of adjustment and adaptation serves as a model to integrate new innovation for building human habitats. These ideas have redefined a conventional construction for building houses where bricks and woods are now mixed with Styrofoam for building materials.

The idea of adaptation and adjustment is germane for us to find ways to minimize human induced degradation of the environment and a way to do it is recycle. Derksen and Gartrell (1993) note that the concern for the environment and pro-environment attitudes are becoming a cultural norm; socially accepted and desired. Present environmental awareness helps policy makers to introduce a variety of recycle programs to benefit the private and public sectors. For instance, a program such as Residential Recycling promotes compliances with regulations for proper removal of hazardous materials from residential appliances prior to recycling the metal components. Some rules may apply to ban major appliances such as refrigerators, water heaters, washers, dryers and air conditioners from landfill disposal and require them to be recycled for their metal content. This program helps residents to avoid any possible harm contact from hazardous materials such as mercury which can be found in switchers and temperature control devices, oils, PCB capacitors and refrigerants.

Recycling program is one of the ways to waste management. It helps us maintain as well as sustain a healthy environment. Setting rules and providing facilities for easy recycling programs are modes likely to be adopted by policy makers. Thus, recycling programs reach their expectant up to the stage where materials are recycled back to their nature of usage. For instance, recycled metals are turned into metals. The idea to enhance the utilization of recycle materials may not be a new invention but it opens a new opportunity to rethink about how to turn recycled materials into something else; more useful and beneficial. Therefore, Polystyrene materials such as Styrofoam may have something to offer.

\subsection{Styrofoam for Possible Human Habitat}

One World Theatre in Austin, Texas has been complimented for its excellent sound that reverberates off the curved back wall to create a cool and beautiful sound. Audiences are impressed how cozy the theatre isremoved from the traffic and scorching temperature of Texas. The building is made of Rastra, a composite of recycled polystyrene, cement and concrete. Rastra was created by a group of European engineers in 1972. The material is becoming popular, parallel with the green movements that are vigorously vocal in promoting environmentally friendly buildings. Rastra is resistant to high winds and laboratory tests have shown that it can withstand a simulated earthquake of 8.5 on the Richter scale. In addition, Rastra is also remarkable insulator, energy efficient, indestructible and fireproof. These combinations make Rastra valuable as a building material. In fact, more than $80 \%$ of its composition is foam and this makes it even better for free pest control zones. It keeps buildings free from termites, mold or other insects.

According to Kahn (2006)-a standard Rastra block is 10 feet long, 10 inches thick and 15 inches high. This porous, pumice like blocks are stacked, either horizontally or vertically and held in place with urethane glue or metal staples. Steel rebar and poured concrete are then inserted into the form at 15 -inch intervals. Despite its blocky beginnings, Rastra can be formed into almost any shape using simple tools, so making rounded walls, niches, pop-outs and circular windows is much easier than with wood framing or cinder block. Green living is becoming one of the hottest lifestyle presently in the United States of America. Most buildings in the United States which are more than 6,000 structures-ranging from a traditional three-bedroom house in the Poconos to a four-story block of loft apartments in Portland, Oregon-have been built using Rastra (Kahn, 2006). Therefore, Polystyrene is evidential for reliable and efficient materials for building human habitat. 
Another interesting finding is a study performed by Brock University in Canada that legitimizes the advantages of Styrofoam as a solid insulation material in Structural Insulated Panels (SIPs). SIPs are two sheets of plywood or Oriented Strand Board (OSB) with a thick layer of polystyrene foam insulation sandwiched between them. These panels offer less amount of wood used in a stick-built structure and $2 \frac{1}{2}$ times stronger. A 6-inch-thick SIPs roof can stand an amount of loads up to 135 pounds per square foot depending on the truss system supporting the SIPs. The application of marine glue to the panels makes it long lasting and strong because marine glue contains less formaldehyde which causes little out-gassing concern. Furthermore, SIPs offer additional advantages such as preserving heat, insulating qualities and dampening sound. These panels prevent air movement in the insulation which preserves better heating system during winter. Because SIPs resist air flow and the humidity that travels with it, homeowners can be better control the humidity levels inside a SIP building. SIPs also dampen sounds which allow homeowners to enjoy a quiet home environment. External noise can be restrained from penetrating the building while in-house music can travel better throughout the house and could become a therapeutic healer.

Rastra and SIPs posses good quality for buildingmaterials but also has a downside-the price of having environmentally friendly building is costly. Good criteria such as energy efficient, insect-proof materials, indestructible and easy to mold make them expensive. However, cost can be redefined when recycle Styrofoam can be maximized when supply is high. Policy makers could enforce new rules and regulation associated with Styrofoam. They can make law abiding to environment by providing facilities to collect used Styrofoam for recycle. Managing recycle Styrofoam has to begin at prepared food-wares businesses, residential areas and every public and private building in town. Because a big scale collection of Styrofoam provide good supplies for new recycled forms of usage. First, authorities have to identify areas that have high percentage of used Styrofoam in daily basis for collection. This may help authorities to determine numbers of facilities needed for processing waste Styrofoam. Second, authorities have to give symbol and label to differentiate types of polystyrene. This method helps recycling centers to distinguish other forms of polystyrene including Styrofoam for various usages. In fact, initial determination on types of polystyrene helps to ease the sorting and separating waste materials to be processed.
In order to ensure the recycling programs for polystyrene works, authorities have to play a proactive role in managing and administering the programs. Cooperation between public and private organizations could be a productive mechanism to warrant the continuity of the program. Furthermore, incentive from the public and private sectors may help inventors to increase the use of Styrofoam. Besides SIPs, Styrofoam can be recycled for notice board, partition panels for office used and low cost houses that are cozy and environmentally efficient. For warm weather climate, SIPs may not be feasible, but other uses of Styrofoam with an appropriate combination of other construction materials can turned into a roof layering material that is water proof and light. It provides an effective way to avoid rook-leaking during rainy seasons.

Therefore, a more consequential approach in managing waste materials such as polystyrene particularly Styrofoam should be discussed. Since Styrofoam offers a variety of benefits that one's could have had expected, the way of managing supply and availability of these materials for future use is vital. Movements to alert humans on the importance of environment for sustainable development have occupied every inch of individual life.

Managing waste materials may be easy to say than do. Sorting and separating waste materials for recycling may be a simple step to follow but lack of knowledge about recycling and individuals' attitude towards environment may impede the process of waste management. Early research on environment and attitudes by Young (1986) focusing on sorting and separating household waste materials by individuals showed disappointment. Individual resources such as concern for the environment, education and self-effort play essential roles to make a systematic program for recycle work (Derksen and Gartrell, 1993). A combination of positive attitude makes sorting and separating for waste materials doable. Although, sorting and separating waste materials are viewed as tedious and tiresome these processes are fundamental in conversion of waste to a profitable product. Further investigations on pro-environment attitudes have shown little relations between socio-demographic variables and recycling behavior (Young and Kaplan, 1985; Vining and Ebreo, 1990). The concern with environment is not cross gender, age and ethnic; it is rather self-awareness and self-effort to ensure a clean environment. However lack of knowledge about recycling could discourage household individuals to sort and separate waste materials. 


\section{CONCLUSION}

As humans produce and create waste materials from their daily use, there are compelling reasons for humans to take necessary actions to ensure that they live in an environment which are clean and safe from harmful wastes. Our existence as a species on this planet is dependent on livability in the environment. If the environment is unsustainable, the quality of life for its species will also deteriorate. Although Styrofoam can be recycled for a good cause, having alternative products to Styrofoam is always encouraged. The benefits for health and environment may outweigh the need of having cost efficient for products like SIPs and Rastra, but if the supply is available and the demand is always out there, Styrofoam may lead other waste materials as the most valuable thrash for industries. As a matter of fact, biodegradable products are still new in the market and therefore limited. It's like counting Hybrid vehicles to ordinary vehicles; the latter outnumbers the former.

\section{REFERENCES}

Colwell, R.K., 1984. What's New? Community Ecology Discovers Biology. In: A New Ecology: Novel Approaches to Interactive Systems, Wiley, P.W., C.N. Slobodchikoff and W.S. Gaud, (Eds.)., Wiley, New York, ISBN-10: 0471896705, pp: 387-396.

Colwell, R.K., 1992. Making sense of ecological complexity: A personal and conceptual restrospective. Biotropica, 24: 226-232. www.jstor.org/stable/2388516

Denevan, W.M., 1983. Adaptation, variation and cultural geography. Profes. Geogr., 35: 399-407. DOI: 10.1111/j.0033-0124.1983.00399.x

Derksen, L. and J. Gartrell, 1993. The social context of recycling. Am. Sociol. Rev., 58: 434-442.

Kahn, J., 2006. Going Green: Its Rastra. New York Times.
Margalef, R., 1968. Perspectives in Ecological Theory. 1st Edn., University of Chicago Press, Chicago, pp: 111.

May, R.M. and J. Seger, 1986. Ideas in ecology. Am. Sci., 74: 256-267.

Moorthy, R., E.A. Choy, S. Selvadurai and N. Lyndon, 2011. Bioethics principles in the teaching of climate change. Am. J. Applied Sci., 8: 962-966. DOI: 10.3844/ajassp.2011.962.966

Odum, H.T., 1983. Systems Ecology: An Introduction. 1st Edn., Wiley, New York, ISBN-10: 0471652776, pp: 644.

Schutt, R.K., 2008. Investigating the Social World: The Process and Practice of Research. 6th Edn., Pine Forge Press, Thousand Oaks, California, ISBN-10: 1412969409, pp: 728.

Smith, E.A., 1984. Anthropology, Evolutionary Ecology and the Explanatory Limitations of the Ecosystem Concept. In: The Ecosystem Concept in Anthropology, Moran, E.F. (Ed.). Westview Press, Boulder, Colorado, ISBN-10: 0865317216, pp: 5186.

Vining, J. and A. Ebreo, 1990. What makes a recycler? A comparison of recyclers and nonrecyclers. Environ. Behav., 22: 55-73. DOI: $10.1177 / 0013916590221003$

Worster, D., 1990. The ecology of order and chaos. Environ. History Rev., 14: 1-18.

Young, R.D. and S. Kaplan, 1985. Conservation behavior and the structure of satisfactions. J. Environ. Syst., 15: 233-241. DOI: 10.2190/R4QKMU4Q-G7W1-MFVU

Young, R.D., 1986. Some psychological aspects of recycling: The structure of conservationsatisfactions. Environ. Behav., 18: 435-449. DOI: $10.1177 / 0013916586184001$

Zimmerer, K.S., 1994. Human geography and the "new ecology": The prospect and promise of integration. Annals Assoc. Am. Geograp., 84: 108-125. 